\title{
Güneydoğu Anadolu Bölgesi Hububat Alanlarında Bulunan Cercopis sanguinolenta (Scopoli, 1763) (Hem.: Cercopidae)'nın Yayılışı ve Yoğunluğu Üzerine Notlar
}

\author{
Çetin Mutlu $^{1 *} \quad$ Abdurrahman Sami Koca ${ }^{2}$ Ünal Zeybekoğlu³ \\ ${ }^{1}$ Harran Üniversitesi, Ziraat Fakültesi, Bitki Koruma Bölümü, Şanlıurfa \\ ${ }^{2}$ Abant İzzet Baysal Üniversitesi, Ziraat ve Doğa Bilimleri Fakültesi, Bitki Koruma Bölümü, Bolu \\ ${ }^{3}$ Ondokuz Mayıs Üniversitesi, Fen Edebiyat Fakültesi, Biyoloji Bölümü, Samsun
}

Geliş tarihi (Received): 16.08.2017Kabul tarihi (Accepted): 04.09.2017

\begin{abstract}
Anahtar kelimeler:
Cercopis sanguinolenta,

hububat, Güneydoğu

Anadolu Bölgesi, yayılış,

yoğunluk

Özet. Bu çalışma; 2014-2015 yıllarında Güneydoğu Anadolu Bölgesi'nde Cercopidae

familyasına ait Cercopis sanguinolenta (Scopoli 1763) (Hemiptera: Auchenorrhyncha) türünün yayılış ve yoğunluklarının belirlenmesi amacıyla yapılmıştır. Adıyaman, Diyarbakır, Mardin ve Şanlıurfa illeri buğday ve arpa ekiliş alanlarından, Nisan ve Mayıs aylarında örneklemeler yapılarak bu türe ait bireyler toplanmıştır. Cercopis sanguinolenta'nın toplam birey sayısı ve ortalama yoğunluğu en fazla Mardin ilinde (toplam 3.050 ergin, 105.2 ergin tarla), en az ise Diyarbakır ilinde (toplam 252 ergin, 7.0 ergin tarla) elde edilmiştir. Arpa alanlarında C. sanguinolenta'nın buğday alanlarına göre daha fazla bulunduğu ve bu oranın

\section{Some Additional Notes on Density and Distribution of Cercopis sanguinolenta (Scopoli, 1763) (Hem.: Cercopidae) in Cereals Cultivated Areas of Southeast Anatolia Region, Turkey}

\section{Keywords:}

Cercopis sanguinolenta, cereal, South East Anatolia Region, density, distribution

\begin{abstract}
This study was conducted to determine the species, density and distribution of Cercopis sanguinolenta (Scopoli 1763) belonging to Cercopidae (Hemiptera: Auchenorrhyncha) in Southeast Anatolia of Turkey in 2014 and 2015. Cercopis sanguinolenta adults were collected from wheat and barley fields of Adıyaman, Diyarbakır, Mardin, Şanlıurfa during April and May. The results revealed that the most number and density of $C$. sanguinolenta were in Mardin province (total 3.050 adult, 105.2 adult field), while the minumum number and density of the spittle bug were determined in Diyarbakır province (total 252 adult, 7.0 adult field) respectively. Besides, it was determined that barley fields were more of C. sanguinolenta than wheat fields and this ratio was 94.9 individual field and 22.8 individual field, respectively. Consequently, some studies should be done about the damage of $C$. sanguinolenta on cereal fields where the spittlebug has high population.
\end{abstract}


Mutlu ve ark., Güneydoğu Anadolu Bölgesi Hububat Alanlarında Bulunan Cercopis sanguinolenta (Scopoli, 1763) (Hem.: Cercopidae)'nın Yayılışı ve Yoğunluğu Üzerine Notlar

\section{GíRiş}

Çayır köpük veya köpüklü ağustos böcekleri olarak bilinen cercopidler, Hemiptera takımı Auchenorrhyncha alt takımına bağlı geniş bir familyadır. Bazı türlerinin gerek nimf, gerekse erginlerinin kurbağayı andırması nedeniyle yabancı literatürlerde "froghoppers" ismi de verilmektedir (Hamilton 1982). Bu familya içinde Avrupa ve yakın doğu ülkelerine ait takriben 33 tür olduğu ve ülkemizde ise bilinen türlerin sayısının 10'dan fazla olduğu bilinmektedir (Lodos 1986). Bu familyaya ait böcekler genellikle küçük ve orta boyda olup erginleri renkli ve desenli kanatlara sahiptir. Bazı türleri polifag olan cercopidler, genellikle Graminae ve diğer otsu bitkilerden ağaç ve ağaççıklara kadar farklı habitatlarda (çayırlar, dağlar, bataklıklar, parklar, orman kenarları, yol kenarları) bulunmaktadırlar (Weaver and King 1954; Lodos and Kalkandelen 1981; Hamilton 1982; Lodos 1986; Zeybekoğlu et al., 2004). Köpüklü ağustos böcekleri beş nimf dönemi geçirmekte ve nimflerinin çoğunun etrafı tükürük veya köpük şeklinde bir sıvı ile örtülüdür. Bu sıvı sadece nimfler tarafından salgılanır ve bu sıvı altında bulunan nimfler devamlı bir şekilde ıslak bir ortam sağlayarak yaşama şartlarına uymaktadırlar. Cercopid türlerinin ergin ve nimflerinin bulundukları bitkilerin sap, ince dal ve sürgünlerini sokup emmek suretiyle onların zayıflamalarına, dolaylı olarak ta verim kaybına yol açmaktadırlar (Weaver and King 1954; Hamilton 1982; Lodos 1986). Graminae familyası bitkilerinin saplarında beslendiklerinde ise saplar kısa kalmakta ve başaklar normal olarak oluşamamakta veya taneleri cilız kalmaktadır.

Türkiye'de bu familyaya ait ekonomik anlamda zararlı olan türün Philaenus spumarius (L.) olduğu ve bazı kültür bitkilerinde yoğun olarak bulunmakla beraber çok geniş bir alana yayıldığı kayıt edilmiş ve aynı zamanda bazı virüs hastalıklarının da vektörü olduğu bildirilmiştir (DeLong et al., 1950; Lodos and Kalkandelen 1981, Zeybekoğlu et al., 2004). Cercopidae türlerinin kültür bitkilerinde genellikle zararsız olduğu belirtilmiş ise de (Hamilton 1982), bunların bitkilerde meydana getirdikleri zarar ile ilgili yeterli kayıt bulunmamaktadır. Cercopidlerin genel olarak kurak iklim koşullarında zararının daha çok arttığı tespit edilmiştir (Lodos 1986). Ayrıca nimflerin beslenirken salgıladıkları toksik maddeler nedeniyle bitkilerde şekil bozuklukları meydana gelmekte ve ekonomik zarar daha çok artmaktadır (Weaver and King 1954; Hamilton 1982). Nispeten diğer bölgelere göre daha kurak ve sıcak olan Güneydoğu Anadolu Bölgesi hububat alanlarında son yıllarda yapılan sürveylerde özellikle Nisan ve Mayıs aylarında bu familyaya ait böceklerin yoğunluklarında bir artış söz konusu olmuştur (alan gözlemi). Ülkemizde pek ender görüldügü bildirilen $C$. sanguinolenta'nın Güney ve Orta Avrupa'da yayıldığı, ergin ve nimflerinin çeşitli bitkilerde görülmesine rağmen ekonomik düzeyde zarar yaptığına dair bir kayıt bulunmamaktadır (Lodos 1986). Bununla beraber bölgede bazı çiftçilerce hububat alanlarında sıklıkla görülen tükürük böcekleri zararlı olarak görülmekte ve bunlara karşı bilinçsizce kimyasal mücadele yapılmaktadır. Bu durum faydalızararlı böcek bakımından kritik dengeye sahip Güneydoğu Anadolu Bölgesi buğday ekosistemlerini olumsuz yönde etkilemektedir (Karaca ve ark., 2012). Bu çalışma 2014-2015 yıllarında, hububat üretimin yoğun olarak gerçekleştirildiği Diyarbakır, Adıyaman, Mardin ve Şanlıurfa illerindeki buğday ve arpa alanlarında bulunan Cercopidae türleri ve bu türlerin yaygınlık ve yoğunluklarının belirlenmesi amacıyla yapılmıştır.

\section{MATERYAL VE METOD}

Çalışmanın ana materyalini, Cercopis sanguinolenta erginleri, Diyarbakır, Adıyaman, Mardin ve Şanlıurfa illerindeki buğday ve arpa ekiliş alanları, atrap, polietilen şeffaf torba ve diğer laboratuvar malzemeleri oluşturmuştur.

\section{Cercopis sanguinolenta Türünün Morfolojik Teşhis Yöntemi ile Belirlenmesi}

Toplanan materyallerin teşhisleri için taksonomik yönden güvenilir karakterlerini genital yapılar oluşturmaktadır. Bu nedenle erkek ve dişi materyallerin genital yapılarının bulunduğu yedinci abdomen segmentinden sonraki kısım vücuttan ayrılmıştır. Erkeklerde aedeagus, stylus, pygofer, genital levha, pregenital sternit ve dişilerde yedinci pregenital sternitin şekli ve yapısı önemli karakterleri oluşturmaktadır. Materyallerin genital yapılarının özellikleri ile birlikte vücut yapısı, şekli, renk ve desenlenme özellikleri mikroskopta incelenmiş ve literatür bilgileri ile kıyaslanarak teşhisleri yapılmıştır. Tür teşhisi Prof. Dr. Ünal Zeybekoğlu (Ondokuz Mayıs Üniversitesi Fen-Edebiyat Fakültesi Biyoloji Bölümü) tarafından yapılmıştır.

\section{Cercopis sanguinolenta Türünün Yayılış ve Yoğunluklarının Belirlenmesi}

Cercopis sanguinolenta Cercopidae türünün yayılış ve yoğunluklarının belirlenmesi çalışmaları 2014-2015 yıllarında bölgede yoğun hububat ekilişi olan 
Mutlu ve ark., Güneydoğu Anadolu Bölgesi Hububat Alanlarında Bulunan Cercopis sanguinolenta (Scopoli, 1763) (Hem.: Cercopidae)'nın Yayılışı ve Yoğunluğu Üzerine Notlar

Diyarbakır ili (Merkez, Bismil, Ergani), Şanlıurfa ili (Siverek, Hilvan, Merkez), Mardin ili (Derik, Kızıltepe, Nusaybin), Adıyaman illerinde (Merkez, Besni, Kâhta) yürütülmüştür. Çalışmalara Nisan ayı ortasında başlanmış olup, buğday hasadının başladığı Mayıs ayı sonunda tamamlanmıştır. Bu aylar içinde farklı tarihlerde iki defa örnekleme yapılmıştır. Yapılan sürveylerde il ve ilçeler arasındaki karayolları izlenmiş, örneklemeler için ekiliş alanlarının durumuna göre 5 km'de bir yolun iki yanındaki hububat alanlarında devam etmiştir. Belirlenen her bir tarlanın içerisinde zikzak çizilerek toplam 100 atrap sallanmış, örnek alınan yer, tarih, hububat cinsi ve fenolojisi ayrıca kaydedilmiştir. Yakalanan Cercopis sanguinolenta örnekleri polietilen şeffaf plastik torbalara konularak laboratuvara getirilmiştir. Derin dondurucuya konularak öldürülen böcekler içinde morfolojik olarak farklı desene sahip olan Cercopis sanguinolenta Cercopidae türleri, binoküler mikroskop altında ayırt edilerek teşhis amacıyla ile etiketlenmiştir Cercopis sanguinolenta sayıları ayrı ayrı kaydedilerek bölgedeki yayılış ve yoğunlukları belirlenmiştir.

\section{BULGULAR VE TARTIŞMA}

\section{Cercopis sanguinolenta Türünün Morfolojik Teşhis Yöntemi ile Belirlenmesi}

Çizelge 1 'de görüldüğü üzere örnekleme yapılan dört il ve on iki ilçenin hububat alanlarından elde edilen çok sayıda bireyin morfolojik teşhisleri sonucunda Güneydoğu Anadolu Bölgesi hububat alanlarında bulunan Cercopid türünün Cercopis sanguinolenta olduğu kayıt edilmiştir (Şekil 1).

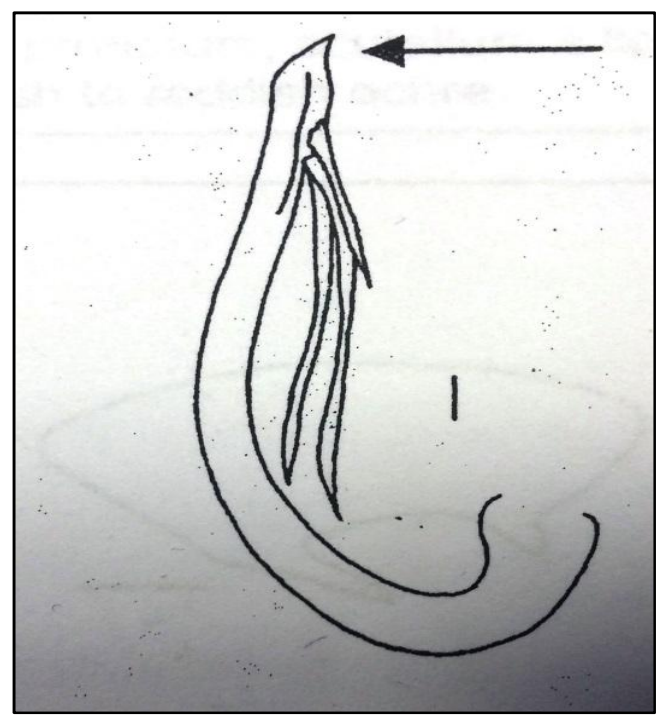

Şekil 1. Cercopis sanguinolenta'da aedeagus (Biederman and Niedringhaus 2009).

Figure 1. The aedeagus of Cercopis sanguinolenta (Biederman and Niedringhaus 2009).

\section{Yayılışı ve konukçuları}

Başta Güney ve Orta Avrupa olmak üzere, Arnavutluk, Avusturya, Belçika, Bulgaristan, Hırvatistan, Çekya, Fransa, Almanya, Yunanistan, Macaristan, İtalya, Moldova, Polonya, Portekiz, Romanya, Güney Rusya, Slovakya, Slovenya, İspanya, İsviçre, Ukrayna ve Sırbistan. Türkiye'de Konya (Kadınhanı) (Lodos 1986; Altınayar 1981). Hububat, Süpürge otu (Cytisus scoparius), Yonca (Medicago sativa), Böğürtlen (Rubus fructicosus), Armut türleri (Pyrus communis, P.malus), Kestane (Castanea vesca) ve çeşitli yabancıotlar (Lodos and Kalkandelen 1981; Nickel and Remane 2002; Orosz 2008).

\section{Tanımı}

Vücut siyah ve mavimsi madensel parıltılıdır. Hemielytra kırmızı desenlidir; clavus'un kaidesinden kırmızı itibaren yarısı, corium'un ortasındaki lekeler ve nihayete yakın olan bant renktedir. Femur'ların her tarafı siyah renktedir (Şekil 2). Vücut uzunluğu 8-10 mm'dir. Bu türün Arnavutluk, Avusturya, Belçika, Bulgaristan, Hırvatistan, Çekya, Almanya, Yunanistan, Macaristan, İtalya'da yayılış gösterdiği bildirilmiştir (Lodos ve Kalkandelen 1981).

Cercopis sanguinolenta'ya yurdumuzda ender olarak rastlanıldığı, Güney ve Orta Avrupa'da yayılış gösterdiği, ergin ve nimflerinin muhtelif bitkilerde görülmesine rağmen ekonomik düzeyde bir zarar yaptığına dair bir kayıt bulunmadığı bildirilmiştir (Lodos 1986). Ülkemizde Cercopidae türlerinden Philaenus spumaris L., Cercopis intermedia Kirschb., C. vulnerata Rossi, Neophilaenus campestris Fall., N. minor Kirschb., Aphrophora salicina Goeze, A. alni Fall., A. corticea Germ., A. exoleta Horv., Lepyronia coleoptrata (L.), Triecphorella geniculata (Horvath 1881)'nın olduğu kayıt edilmiştir (Lodos 1986; Demir 2006; 2007). Yukarıdaki çalışmalardan elde edilen bu türlerden C. intermedia ve L. coleoptrata 'nın Diyarbakır ilinde bulunduğu, C. vulnerata'nın daha çok Marmara Bölgesi'nin bazı kesimlerinde, Neophilaenus cinsine bağlı türlerin Batı Anadolu kesimlerinde, Aphrophora cinsine bağlı türlerin ise Doğu Karadeniz Bölgesi'nde yayılış gösterdikleri bildirilmiştir (Lodos and Kalkandelen 1981; Lodos 1986). Kaya ve Kovancı (2004), Bursa ili ahududu alanlarında Cercopidae familyasına ait 8 türün belirlendiğini, bunlardan $P$. spumaris'in popülasyonun oldukça yüksek olduğu, Altınayar (1981), C. sanguinolenta ve C. vulnerata 'nın polifag olduğunu ve Orta Anadolu hububat alanlarında bulunduğunu bildirmişlerdir. Bu çalışmada daha önce Diyarbakır ilinde varlığı bildirilen C. intermedia ve L. Coleoptrata ek olarak C. 
Mutlu ve ark., Güneydoğu Anadolu Bölgesi Hububat Alanlarında Bulunan Cercopis sanguinolenta (Scopoli, 1763) (Hem.: Cercopidae)'nın Yayılışı ve Yoğunluğu Üzerine Notlar

sanguinolenta kayıt edilmiştir. Ancak bu türe ait farklı varyasyonların olması ihtimaline karşı morfolojik teşhisler ile birlikte moleküler teşhis yöntemlerinden faydalanılması gerektiği düşünülmektedir.
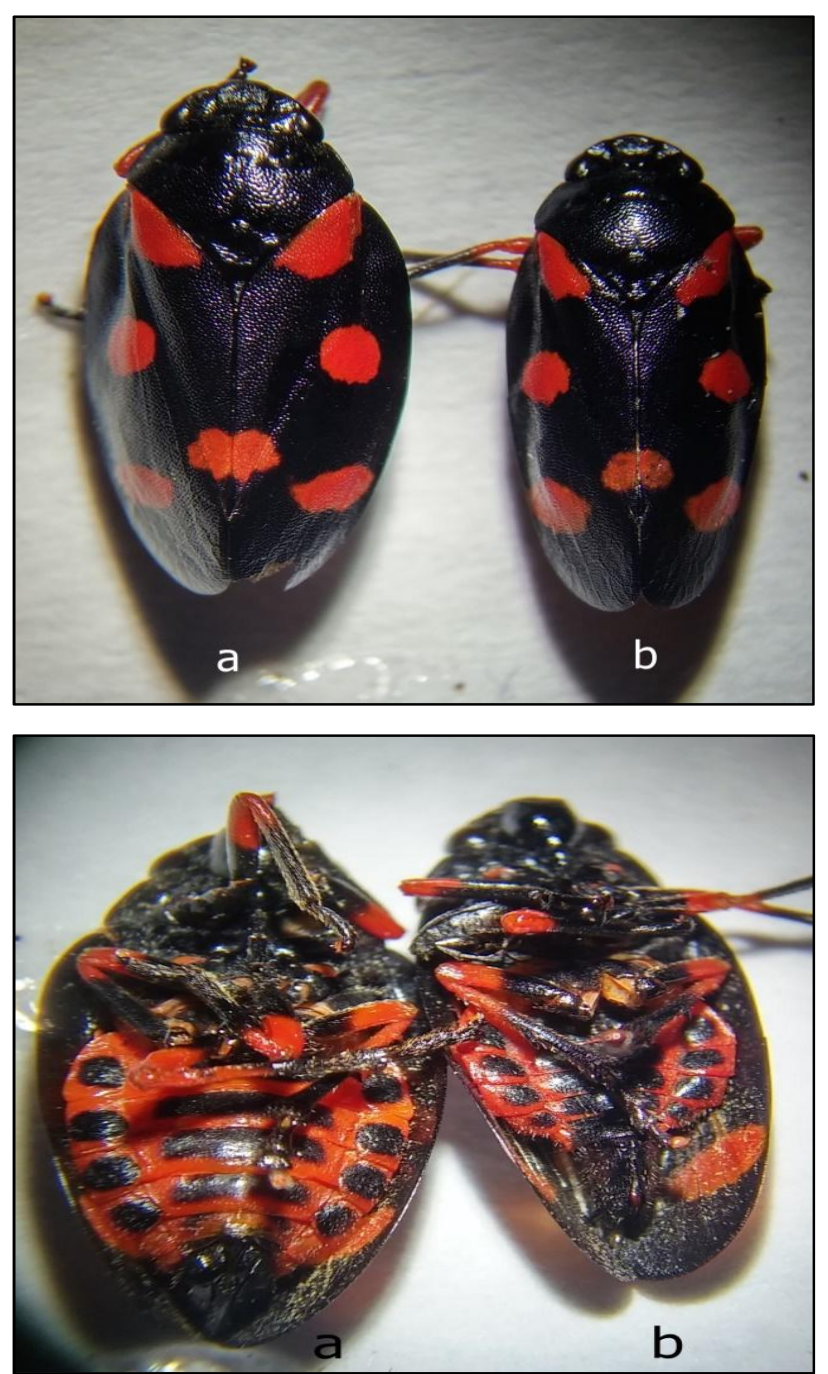

Şekil 2. Güneydoğu Anadolu Bölgesi hububat alanlarında belirlenen Cercopis sanguinolenta bireyleri, a. dişi, b. Erkek. Figure 2. Cercopis sanguinolenta adults determined Southeast Anatolia Region cereals cultivated areas, $a$. female, $b$. male.

\section{Cercopis sanguinolenta Türünün Yayılış ve Yoğunluklarının Belirlenmesi}

Güneydoğu Anadolu Bölgesi hububat alanlarında örnekleme yapılan yerler ve elde edilen $C$. sanguinolenta birey sayılarına ait sonuçlar Çizelge 1 'de verilmiştir.

Sürveyler sonucunda 2014 yılında, örnekleme yapılan toplam 71 adet tarlanın \%79'unda C. sanguinolenta erginlerine rastlanılmış (56 tarla), \%21' inde ise ergin bulunamamıştır (15 tarla). İkinci yıl çalışmalarında (2015 yılı), sürvey yapılan hububat tarlalarının \%71'inde C. sanguinolenta erginleri belirlenmiş (46 tarla), \%29'unda ise C. sanguinolenta belirlenememişsir. Çalışmanın birinci yılında toplam
2.640 birey, ikinci yılında ise 1.840 adet birey elde edilmiştir.

Güneydoğu Anadolu Bölgesi hububat alanlarında elde edilen $C$. sanguinolenta ortalama birey sayılarına ait sonuçlar Şekil 3'te verilmiştir.

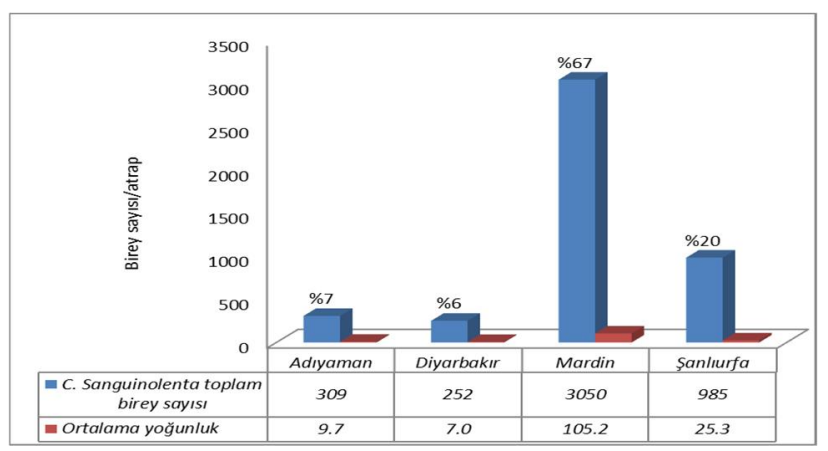

Şekil 3. Güneydoğu Anadolu Bölgesi hububat alanlarından elde edilen C. sanguinolenta toplam birey sayısı ve yoğunlukları.

Figure 3. Total numbers of adult C. sanguinolenta collected from cereals cultivated areas of South East Anatolia Region.

Her iki yılı kapsayan çalışmalar birlikte değerlendirildiğinde örnekleme yapılan dört ilin buğday ve arpa alanlarından toplam 4.538 birey elde edilmiştir. En fazla C. sanguinolenta Mardin ilinde (3.050 birey), en az ise Diyarbakır ilinde (252 birey) belirlenmiştir (Şekil 3). Buna göre C. sanguinolenta toplam birey sayısının \%67'si Mardin ilinden, \%7'si Diyarbakır ilinden toplanmıştır. IIller arasındaki $C$. sanguinolenta yoğunlukları karşılaştırıldığında, en fazla yoğunluğun (Ort. 105.2 birey tarla) Mardin ilinde olduğu en az ise Diyarbakır ilinde (Ort. 7.0 birey tarla) olduğu kayıt edilmiştir. Mardin ilinden sonra aynı ekolojik koşullara sahip Şanlıurfa ilinde (Ort. 23.8 birey tarla) Adıyaman ve Diyarbakır iline göre yoğunluğun yüksek olduğu tespit edilmiştir.

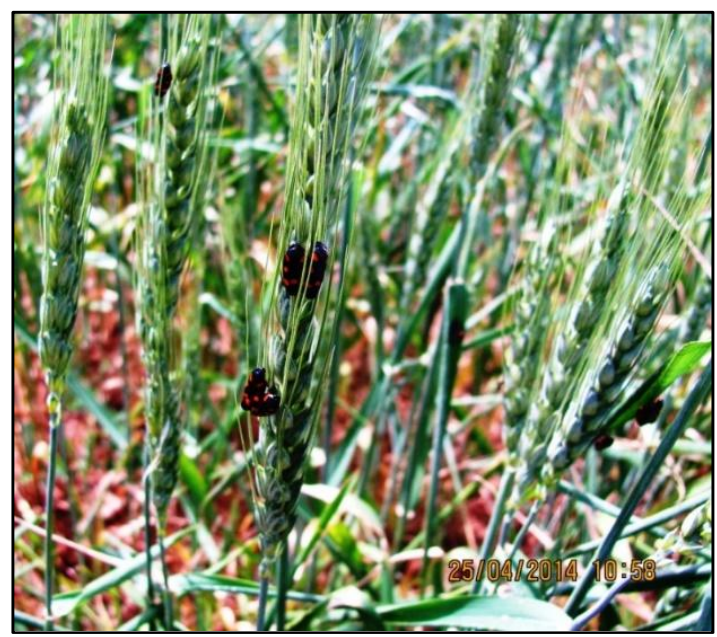

Şekil 4. Mardin ilinde Buğday başakları üzerinde bulunan C. sanguinolenta erginleri.

Figure 4. Cercopis sanguinolenta adults on wheat spikes in Mardin Province. 
Mutlu ve ark., Güneydoğu Anadolu Bölgesi Hububat Alanlarında Bulunan Cercopis sanguinolenta (Scopoli, 1763) (Hem.: Cercopidae)'nın Yayılışı ve Yoğunluğu Üzerine Notlar

Çizelge 1. Güneydoğu Anadolu Bölgesi'nde 2014-2015 yıllarında C. sanguinolenta'nın yayılış ve yoğunlukları.

Table 1. The density and distribution of C. sanguinolenta in South East Anatolia Region in 2014-2015.

\begin{tabular}{|c|c|c|c|c|c|}
\hline Yıl & il & ilçe & $\begin{array}{l}\text { Örneklenen } \\
\text { alan }\end{array}$ & $\begin{array}{l}\text { Örnekleme } \\
\text { yapılan Tarla } \\
\text { sayısı }\end{array}$ & $\begin{array}{l}\text { Cercopis } \\
\text { sanguinolenta } \\
\text { birey sayısı }\end{array}$ \\
\hline 2014 & Adıyaman & Besni & Buğday-Arpa & 6 & 69 \\
\hline 2014 & Adıyaman & Kâhta & Buğday-Arpa & 5 & 84 \\
\hline \multirow[t]{2}{*}{2014} & Adıyaman & Merkez & Buğday-Arpa & 6 & 74 \\
\hline & & & Toplam & 17 & 227 \\
\hline 2014 & Diyarbakır & Bismil & Buğday-Arpa & 7 & 51 \\
\hline 2014 & Diyarbakır & Ergani & Buğday-Arpa & 7 & 79 \\
\hline \multirow[t]{2}{*}{2014} & Diyarbakır & Merkez & Buğday-Arpa & 8 & 58 \\
\hline & & & Toplam & 22 & 188 \\
\hline 2014 & Mardin & Derik & Buğday-Arpa & 3 & 132 \\
\hline 2014 & Mardin & Kızıltepe & Buğday-Arpa & 6 & 351 \\
\hline \multirow[t]{2}{*}{2014} & Mardin & Nusaybin & Buğday-Arpa & 5 & 1373 \\
\hline & & & Toplam & 14 & 1.856 \\
\hline 2014 & Şanlıurfa & Hilvan & Buğday-Arpa & 7 & 249 \\
\hline 2014 & Şanlıurfa & Merkez & Buğday-Arpa & 4 & 76 \\
\hline \multirow[t]{3}{*}{2014} & Şanlıurfa & Siverek & Buğday-Arpa & 7 & 102 \\
\hline & & & Toplam & 18 & 427 \\
\hline & & & Genel Toplam & 71 & 2.698 \\
\hline 2015 & Adıyaman & Besni & Buğday-Arpa & 5 & 26 \\
\hline 2015 & Adıyaman & Kâhta & Buğday-Arpa & 4 & 24 \\
\hline \multirow[t]{2}{*}{2015} & Adıyaman & Merkez & Buğday-Arpa & 6 & 32 \\
\hline & & & Toplam & 15 & 82 \\
\hline 2015 & Diyarbakır & Bismil & Buğday-Arpa & 5 & 32 \\
\hline 2015 & Diyarbakır & Ergani & Buğday-Arpa & 5 & 26 \\
\hline \multirow[t]{2}{*}{2015} & Diyarbakır & Merkez & Buğday-Arpa & 4 & 6 \\
\hline & & & Toplam & 14 & 64 \\
\hline 2015 & Mardin & Derik & Buğday-Arpa & 3 & 24 \\
\hline 2015 & Mardin & Kızıltepe & Buğday-Arpa & 5 & 56 \\
\hline \multirow[t]{2}{*}{2015} & Mardin & Nusaybin & Buğday-Arpa & 7 & 1114 \\
\hline & & & Toplam & 15 & 1194 \\
\hline 2015 & Şanlıurfa & Merkez & Buğday-Arpa & 7 & 34 \\
\hline 2015 & Şanlıurfa & Hilvan & Buğday-Arpa & 9 & 476 \\
\hline \multirow[t]{3}{*}{2015} & Şanlıurfa & Siverek & Buğday-Arpa & 5 & 58 \\
\hline & & & Toplam & 21 & 500 \\
\hline & & & Genel Toplam & 65 & 1.898 \\
\hline
\end{tabular}

Örnekleme yapılan buğday ve arpa tarlalarındaki $C$. sanguinolenta birey sayıları ve ortalama yoğunluklarına ait sonuçlar Şekil 5'te verilmiştir.

Arpa tarlalarından toplanan C. Sanguinolenta'nın birey sayısı, buğday alanlarından daha fazla olarak gerçekleşmiş̧ir (Şekil 5). Örnekleme yapılan toplam 136 adet tarlanın 20'sini arpa tarlaları oluşturmuş ve bu rakam örnekleme alanları toplamının \%15'ine denk gelmiştir. 2014 yılında toplam 11 adet arpa tarlasından, 2015 yılında ise toplam 9 adet arpa tarlasından örnek toplanmıştır. Örneklenen arpa tarlalarının sayısal olarak azlığına rağmen, bu alanlardan elde edilen $C$. sanguinolenta birey sayısının oranı, toplam birey sayısına oranı \%42 olarak gerçekleşmiştir.

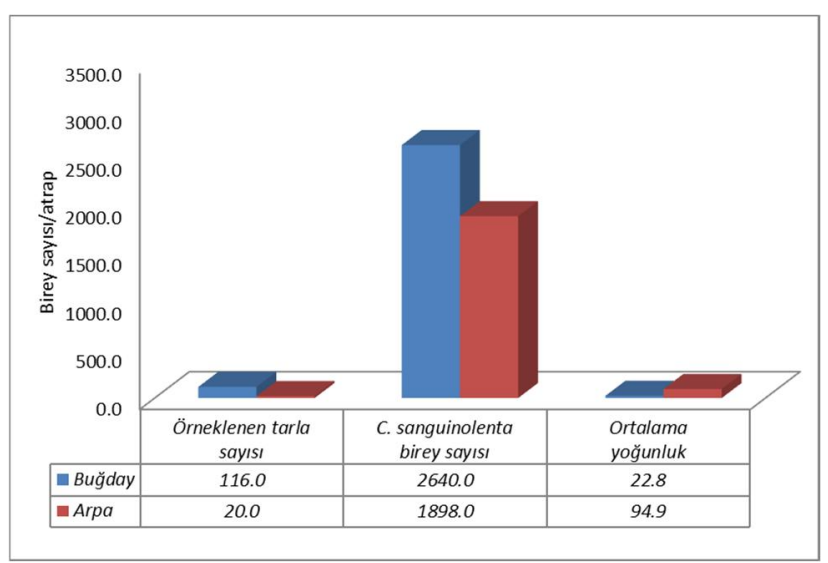

Şekil 5. Cercopis sanguinolenta'nın buğday ve arpadaki ortalama birey sayısı.

Figure 5. The number of mean of $C$. sanguinolenta adults in heat and barley fields. 
Mutlu ve ark., Güneydoğu Anadolu Bölgesi Hububat Alanlarında Bulunan Cercopis sanguinolenta (Scopoli, 1763) (Hem.: Cercopidae)'nın Yayılışı ve Yoğunluğu Üzerine Notlar

Çalışma yapılan iller arasında C. sanguinolenta yoğunluğu en fazla Mardin ilindeki (Nusaybin ilçesi) buğday ve arpa alanlarında olduğu (Çizelge 1) belirlenmiştir. Ancak bu yoğunluğun arpalarda buğdaydan daha fazla olduğu tespit edilmiştir. Cercopid'lerin genel olarak yabancı otlar ve bazı kültür bitkileri üzerinde bulundukları (EFSA 2015), bazı türlerin polifag, bazı türlerin ise belirli konukçu türleri tercih ettikleri bildirilmiştir (Lodos 1986). Iki yıl sürdürülen sürveyler sonucundan Mardin ilinde diğer illere göre elde edilen yüksek birey sayısının nedeninin iklim koşulları ve buğday-arpa monokültürü ile ilgili olduğu düşünülmektedir. Çünkü bölgede ekolojik koşullardan dolayı buğday ve arpa daha erken olgunlaşmakta ve ilk olarak Mardin ilinde özellikle Nusaybin ilçesi ve çevresinde gerçekleşmektedir. Bu bulguyu destekler nitelikte, Cercopid türlerden $P$. spumaris'in özellikle Nisan ve Mayıs aylarında yağışın az ve kurak olan yer veya iklim koşullarında zararı ve yoğunluğunun arttığı bildirilmiştir (Lodos 1986). Başka bir çalışmada ise $P$. spumaris'in yayılış alanının belirlenmesinde nem ve sıcaklığın en önemli faktörler olduğu kaydedilmiştir (Zeybekoğlu ve ark., 2004). Mardin ili dışında diğer illerdeki hububat alanlarında buğday/arpa başakları üzerinde fazla sayıda ergin birey gözlenmemiştir (Şekil 4). Yapılan bir çalışmada $C$. intermedia'nın kuşburnu üzerinde beslendiğini ancak zararın önemsiz olduğunu bildirilmiştir (Özbek ve ark., 1996). Cercopis sanguinolenta'nın ergin ve nimflerine muhtelif bitkilerde bulunmasına rağmen ekonomik düzeyde zarar yaptığına dair bir kayıt olmamakla birlikte, bu çalışmada buğday ve arpanın sapa kalkma ve başaklanma döneminde bazı tarlalarda başaklar üzerinde yoğun bulunmasına karşın ekonomik bir zararı belirlenmemiştir. Sadece yer yer buğday ve arpanın yaprakları üzerinde nimflerin yoğun olarak salgıladığı tükürük veya köpük şeklinde bir sıvı ile kaplandığı belirlenmiştir (Şekil 6).

\section{SONUÇ}

Bu çalışma ile Güneydoğu Anadolu Bölgesi'nde yoğun olarak hububat tarımının yapıldığı Adıyaman, Diyarbakır, Mardin ve Şanlıurfa illerindeki Cercopis sanguinolenta türünün yayılış ve yoğunlukları belirlenmiştir. Çalışmada elde edilen $C$. sanguinolenta toplam birey sayısı ve yoğunluğu en fazla Mardin ilinden elde edilmiştir. Arpa alanlarında C. sanguinolenta'nın buğday alanlarına göre daha fazla bulunduğu belirlenmiştir. Sonuç olarak, Cercopis sanguinolenta popülasyon yoğunluğunun yüksek olduğu Mardin ilinde buğday ve arpada meydana getirdiği zarar durumunun ortaya çıkarılması ve yapılacak eğitim ve yayın çalışmaları neticesinde hububat alanlarında C. Sanguinolenta'ya karşı yapılan gereksiz ilaçlamaların önüne geçileceği düşünülmektedir.

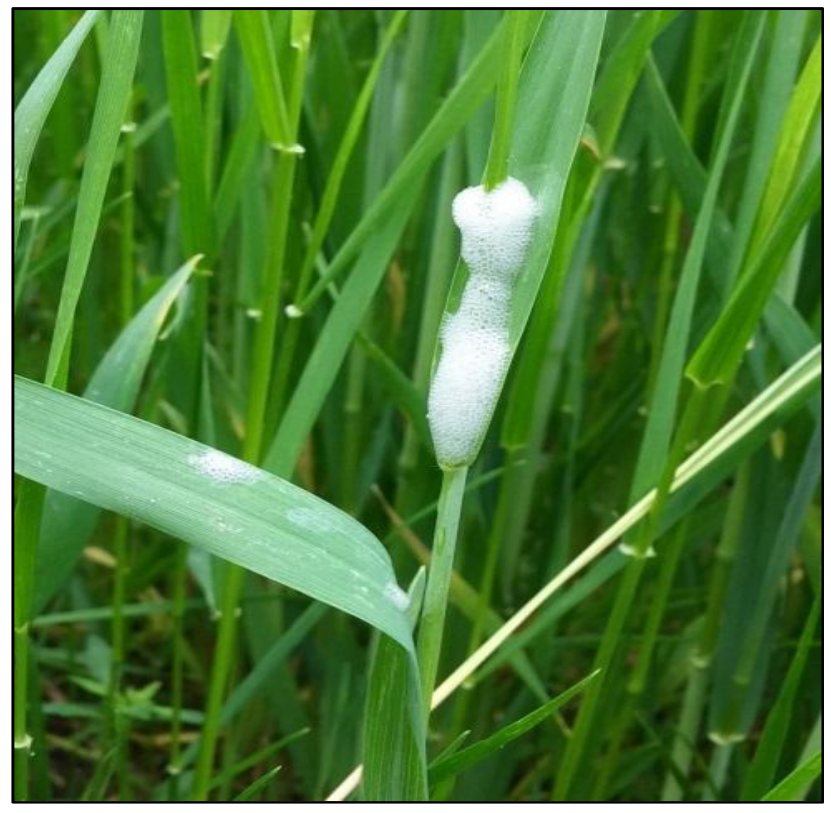

Şekil 6. Cercopis sanguinolenta nimflerinin buğday yapraklarında meydana getirdiği köpük.

Figure 6. Spittle masses on wheat leaves caused Cercopis sanguinolenta nypmhs.

\section{KAYNAKLAR}

Altınayar G., 1981. Orta Anadolu Bölgesi tahıl tarlalarındaki böcek faunasının saptanması üzerinde çalışmalar. Türkiye Bitki Koruma Dergisi, 21(2): 53-88.

Biederman R and Niedringhaus R., 2009. The Plant and Leafhoppers of Germany Identification Keys for all species. WABV Fründ.

DeLong DM and Henry HPS., 1950. Spittle-insect vectors of Pierce's disease virüs: I, characters, distribution, and food plants. Hilgardia, 19(11): 339-376.

Demir E., 2006. Preliminary report on the auchenorrhyncha (hemiptera) fauna of Kazdağı National Park with two new records for Turkey. Acta Entomologica Slovenica, 14(1): 89-102.

Demir E., 2007. Auchenorrhyncha (Homoptera) data from Ankara with two new records to Turkey. Munis Entomology \& Zoology, 2: 481-492.

EFSA, 2015. Scientific Opinion on the risk to plant health posed by Xylella fastidiosa in the EU territory, with the identification and evaluation of risk reduction options. European Food Safety Authority (EFSA) Journal, 13(1): 3989.

Hamilton AKG., 1982. The Insects and Arachnids of Canada Part 10, The Spittlebuqs of Canada. Biosystematics Research Institute Ottawa, Ontario, Publication 1740. 
Mutlu ve ark., Güneydoğu Anadolu Bölgesi Hububat Alanlarında Bulunan Cercopis sanguinolenta (Scopoli, 1763) (Hem.: Cercopidae)'nın Yayılışı ve Yoğunluğu Üzerine Notlar

Karaca V., Gözüaçık C ve Şimşek Z., 2012. Güneydoğu Anadolu Bölgesi'nde hububatın entomolojik sorunları ve çözüm önerileri. Türk Bilimsel Derlemeler Dergisi, 5(2): 154-159.

Kaya M ve Kovancı B., 2004. Bursa'da ahududu alanlarında saptanan Homoptera türleri. Atatürk Üniversitesi Ziraat Fakültesi Dergisi, 35(1-2): 1-4.

Lodos N and Kalkandelen A., 1981. Preliminary list of Auchenorrhyncha with notes on distribution and importance of species in Turkey VI. Families Cercopidae and Membracidae. Türkiye Bitki Koruma Dergisi, 5(3): 133-149.

Lodos N., 1986. Türkiye Entomolojisi II. Genel Uygulamalı ve Faunistik. Ege Üniversitesi Basımevi, İzmir.

Nickel $\mathrm{H}$ and Remane R., 2002. Check list of the planthoppers and leafhoppers of Germany with notes on food plants, diet width, life cycles, geographic range and conservation status (Hemiptera, Fulgoromorpha and Cicadomorpha). Beiträge zur Zikadenkunde, 5: 27-64.
Orosz A., 2008. Contributions to the leafhopper fauna of the protected areas along the river Tur (Homoptera: Auchenorrhyncha). Hungarian Natural History Museum, Budapest, Hungary.

Özbek H., Güçlü \$̧ ve Tozlu G., 1996. Erzurum, Erzincan, Bayburt ve Artvin Illerinde Kuşburnu Bitkisinde Zararlı Olan Arthropoda Türleri. Kuşburnu Sempozyumu, 5-6 Eylül 1996, Gümüşhane.

Weaver CR and King DR., 1954. The meadow spittlebug. Ohio Agricultural Experiment Station, Research Bulletin 741.

Zeybekoğlu Ü., Yurtsever S and Turgut F., 2004. Polymorphism of Philaenus spumarius (L.) (Homoptera, Cercopidae) in the Samsun (Mid-Black Sea Region) populations of Turkey. Annales de la Société Entomologique de France, 40: 277-283. 